\title{
EXPERIMENTALISMO E ANÁLISE INSTITUCIONAL NO CURSO FGV DIREITO RIO: UM PROJETO EM CONSTRUÇÃO ${ }^{1}$
}

\section{EXPERIMENTALISM AND INSTITUTIONAL ANALYSIS IN THE COURSE OF FGV DIREITO RIO: A PROJECT UNDER CONSTRUCTION}

\author{
JOAQUIM FALCÃO ${ }^{2}$ \\ PEDRO DELFINO ${ }^{3}$
}

\begin{abstract}
RESUMO: Em meados de maio de 2015, o Diretor da FGV DIREITO RIO marcou uma reunião com o coordenador da graduação e com um aluno do $5^{\circ}$ período. Depois disso, algumas semanas se passaram e coube ao aluno preparar uma proposta de curso. Em uma nova reunião, o estudante apresentou sua ideia e ela foi implementada com o aval do diretor. Em síntese, a estrutura do DNA de uma instituição é definida pelo que as pessoas fazem e não por aquilo que elas dizem. Se fosse possível estruturar o experimentalismo institucional em uma fórmula, a equação necessariamente exigiria alguma coisa como: (i) uma tolerância ao risco acima da média e (ii) uma postura aberta em relação ao que é diferente. Apenas em um contexto como esse seria possível construir um curso que adotasse como ponto de partida a seguinte premissa: alunos também podem ensinar. $\mathrm{O}$ desenrolar desse experimento são cenas das próximas seções.
\end{abstract}

Palavras-Chave: Direito; Ensino jurídico; Experimentalismo institucional.

ABSTRACT: In mid-May 2015, the Director of FGV DIREITO RIO arranged a meeting with the graduation coordinator and a student of the 5th period. After that, a few weeks passed and it was up to the student to prepare a course proposal. At a new

\footnotetext{
${ }^{1}$ Experimentalismo e análise institucional no curso FGV DIREITO RIO: Um projeto em construção.

${ }^{2}$ Doutor em Educação pela University of Génève. LLM pela Harvard Law School. Graduado em Direito pela PUC-Rio. ex-Diretor da FGV Direito Rio. Professor da Graduação e do Mestrado em Direito da Regulação. Foi Conselheiro do Conselho Nacional de Justiça (2005 a 2009).

3 Graduado em Direito e graduando em Matemática Aplicada pela Fundação Getúlio Vargas. Cofundador do NetLex.
} 
meeting, the student presented his idea and it was implemented with the approval of the principal. In short, the structure of an institution's DNA is defined by what people do and not by what they say. If it were possible to structure institutional experimentalism into a formula, the equation would necessarily require something like: (i) an above-average risk tolerance and (ii) an open stance in relation to what is different. Only in such a context would it be possible to construct a course that would adopt as a starting point the following premise: students can also teach. The unfolding of this experiment are scenes from the next sections.

PAlAvRAS-ChAve: Law; Legal education; Institutional Experimentalism.

\section{UM CAUSO SOBRE COMO TUDO COMEÇOU}

Em meados de Maio de 2015, o Diretor da FGV DIREITO RIO marcou uma reunião com o coordenador da graduação e com um aluno do $5^{\circ}$ período. ${ }^{4} \mathrm{~A}$ conversa começou com a seguinte frase:

- Olha, no próximo semestre eu gostaria de dar uma disciplina. O tema seria educação jurídica. - disse o Diretor.

"Bacana professor, vou me inscrever nessa matéria aí com certeza" - disse o garoto com uma perceptível empolgação.

- Mas tem um detalhe. Eu gostaria que você fosse professor na disciplina junto comigo.

Depois disso, algumas semanas se passaram e coube ao aluno preparar uma proposta de curso. Em uma nova reunião, o estudante apresentou sua ideia.

- Isso é completamente diferente do que eu havia imaginado. Sejamos francos, essa ideia é psicodélica. Mas nós vamos fazer mesmo assim. - disse o diretor rindo.

A estrutura do DNA de uma instituição é definida pelo que as pessoas fazem e não por aquilo que elas dizem. Se for possível estruturar o experimentalismo institucional em uma fórmula, a equação necessariamente exigirá (i) tolerância ao risco e (ii) abertura em relação ao que é diferente..$^{5}$ Apenas nesse contexto é possível construir um curso que adota a seguinte premissa: alunos também podem ensinar. O desenrolar desse experimento são cenas das próximas seções.

\footnotetext{
${ }^{4}$ A história contada acima se passou durante a gestão do Professor Joaquim Falcão como Diretor da FGV DIREITO RIO (2002-2017).

${ }^{5}$ Em torno dos desafios de modernização do ensino jurídico no Brasil, ver: FALCÃO, Joaquim LACERDA, Gabriel; RANGEL, Tânia. Aventura e legado no ensino jurídico. Rio de Janeiro: FGV Direito Rio, 2012.
} 


\section{A NATUREZA RECURSIVA DA DISCIPLINA}

A FGV DIREITO RIO nasceu em 2002 como uma alternativa ao que muitos denominam de crise da educação jurídica brasileira. ${ }^{6}$ Desde o início, a Escola possui uma missão clara: formar juristas que não sejam apenas operadores ou aplicadores do Direito, mas arquitetos do Direito, sendo capazes de desenhar institutos e instituições. ${ }^{7}$

$\mathrm{Na}$ visão dos fundadores, o exercício dessa engenharia institucional exige uma formação jurídica distinta do que é tradicionalmente oferecido nos cursos de Direito do Brasil. No lugar de disciplinas voltadas para fins meramente informativos, acríticos e enciclopédicos, entram abordagens focadas no desenvolvimento de estruturas de pensamento e de habilidades. ${ }^{8}$ Fazendo uma analogia com o universo da computação, para formar engenheiros de instituições é preciso que se tenha uma preocupação maior em tornar o processador mais potente do que em preencher o $H D$ com informações que são, no fim das contas, circunstanciais.

O jurista que cria instituições precisa, sobretudo, de três competências de resolução de problemas: a sensibilidade para identificar um problema, o raciocínio lógicoanalítico para decompô-lo e a criatividade para desenhar um arranjo que o resolva. ${ }^{9}$ Ao longo da graduação, incentivamos essas habilidades nos alunos. Em disciplinas como Sociologia Jurídica, Teoria da Justiça e Direitos Humanos, a competência de perceber um problema é desenvolvida. Em outras matérias, como Análise Econômica do Direito e Teoria da Decisão, a ênfase está na estruturação analítica e na formalização dos problemas. Existem ainda cursos como Processo Decisório no Supremo Tribunal Federal e Introdução ao Estudo do Direito II que focam em raciocínios prospectivos, hipotéticos e criativos sobre novos arranjos institucionais.

No melhor dos cenários, essas habilidades são treinadas e, no futuro, serão aplicadas no ordenamento jurídico brasileiro. O ápice da concretização do projeto pedagógico da Escola ocorrerá se, um dia, um ex-aluno usar essa formação para, por exemplo, redesenhar o arranjo institucional de uma instituição pública ou para criar uma inovadora estrutura societária.

A principal disrupção da disciplina "FGV DIREITO RIO: um projeto em construção" consistiu em criar um espaço de treinamento para essas habilidades de resolução de problemas. Durante o segundo semestre de 2015, cerca de 15 alunos foram convidados a vivenciar o experimentalismo e a análise institucional na prática.

A expressão espaço de treinamento talvez remeta a uma arena onde esportes são praticados. Aqui o sentido se aproxima mais de um laboratório de experimentos científicos. Neste contexto, como todo procedimento experimental, nós tivemos uma

6 DANTAS, F. C. de San Tiago. A Educação Jurídica e a Crise Brasileira. Educação Jurídica e Método de Caso. Série Cadernos FGV Direito Rio, Educação e Direito, v. 3, Rio de Janeiro, Fevereiro de 2009.

7 RODRIGUEZ, Caio Farah; FALCÃO, Joaquim. O Projeto da Escola de Direito do Rio de Janeiro da FGV. Série Cadernos FGV Direito Rio, Educação e Direito, v. 1, Rio de Janeiro, Novembro de 2005.

8 Ibidem.

${ }^{9}$ Sobre a necessidade constante de adaptação do ensino jurídico às exigências do mercado brasileiro, ver: FALCÃO, Joaquim. "Classe dirigente e ensino jurídico: uma releitura de San Tiago Dantas. Em: Cadernos FGV Direito Rio, vol. 3, Rio de Janeiro: FGV Direito Rio, 2009, p. 39-80. 
cobaia a nossa disposição, sendo justamente neste ponto que fica evidente a natureza recursiva do nosso curso.

Na Matemática e na Ciência da Computação, a recursão é uma regra que invoca a si mesma durante a sua execução. No nosso caso, o experimentalismo institucional propagado pela Escola foi recursivo ao usar como cobaia para nossas análises a própria FGV DIREITO RIO e não instituições como a Ordem dos Advogados do Brasil ou o Ministério Público Federal.

Além de representar um processo recursivo, a disciplina também foi construída a partir de outras analogias. O arquiteto de instituições não é um mero operador, ele é co-autor do sistema ao qual está submetido. Desse modo, o jurista que exerce esse papel, em alguma medida, raciocina como Juiz, Legislador e Presidente. Assim, até a própria Constituição da República, a norma mais alta na hierarquia do ordenamento positivo, está passível de ser reescrita.

De forma análoga, o papel que definimos para os nossos alunos nesse curso foi o de estudantes que não fossem apenas usuários do sistema, mas coautores do processo educativo ao qual estão submetidos, tendo a oportunidade de raciocinar como Diretor, Coordenador e Professor. Usando acrônimos, o aluno DCP (Diretor, Coordenador e Professor) nada mais é que uma pequena versão do Jurista JLP (Juiz, Legislador e Presidente).

\section{ESTRUTURA TEMÁTICA}

No início, como sugere o causo, o tema do curso seria educação jurídica. Conforme a disciplina foi sendo desenhada, o foco mudou. Educação jurídica continuou como foco temático mas o conteúdo que seria ministrado deixou de ser o nosso foco estratégico.

O tema educação jurídica se tornou apenas um pretexto para que (i) submetêssemos os alunos a um intenso treino de habilidades de resolução de problemas e (ii) expuséssemos nossa Escola a um experimento. ${ }^{10}$

Essa estrutura foi concretizada em sete encontros, divididos em dois blocos temáticos. No primeiro bloco "Ideias e dados por trás do projeto", as discussões foram voltadas para nossa própria Escola. Na primeira aula do curso, discutimos os textos fundadores escritos por Joaquim Falcão, Caio Farah e Roberto Mangabeira Unger. ${ }^{11}$

A FGV DIREITO RIO, desde a sua fundação, é uma Escola confessional, frequentemente confessando e explicitando sua escolha pedagógica. Ainda que o texto fundador seja conhecido na comunidade de estudiosos da educação jurídica brasileira,

\footnotetext{
10 No contexto de divulgação da disciplina, em Julho de 2015, foi feito um vídeo explicativo que pode ser encontrado em: https://youtu.be/mcGygDBgjRM?t=8s

11 RODRIGUEZ, Caio Farah, FALCÃO, Joaquim. O Projeto da Escola de Direito do Rio de Janeiro da FGV. Projetos para um novo ensino jurídico no Brasil. Série Cadernos FGV Direito Rio, Educação e Direito, v. 1, Rio de Janeiro, Novembro de 2005; UNGER, Roberto Mangabeira, O Projeto da Escola de Direito do Rio de Janeiro da FGV. Projetos para um novo ensino jurídico no Brasil. Série Cadernos FGV Direito Rio, Educação e Direito, v. 1, Rio de Janeiro, Novembro de 2005.
} 
muitos alunos nunca tinham tido a oportunidade de lê-lo e de discuti-lo. O objetivo da aula inaugural foi explorar os fundamentos teóricos e as premissas em que o projeto pedagógico foi construído. Apenas com clareza nesses fundamentos se torna possível elaborar críticas aos ideais da Escola e aos meios com que ela executa seu projeto.

Na segunda aula, denominada "In God we trust, all others must bring data", a discussão teve natureza quantitativa. Reunimos dados da graduação fornecidos pelo Centro Acadêmico, pela Diretoria e pela Coordenação. Os diversos relatórios estatísticos tornaram nítidos alguns problemas e funcionaram como gatilho para a formulação de novas hipóteses.

Como fechamento do primeiro bloco, discutimos um relatório elaborado pelo professor de Harvard Henry Steiner. Em 2011, por cerca de quatorze dias, Steiner assistiu aulas, entrevistou alunos e conversou com funcionários da FGV DIREITO RIO, redigindo um documento em que foram destacados pontos positivos e negativos da Escola naquele momento. $\mathrm{O}$ texto funcionou como uma referência e um exemplo do tipo de sensibilidade e de precisão que gostaríamos de perceber nas discussões. Steiner acompanhou desde as discussões sobre educação jurídica brasileira nos anos 70 até a fundação da Escola, sendo capaz de prestar uma consultoria muito bem fundamentada. Vale notar que, até ser incorporado ao material didático de nosso curso, o relatório de Steiner era de acesso restrito, sendo que apenas alguns membros da nossa comunidade tinham tido a oportunidade de lê-lo.

Se no primeiro bloco a concentração temática foi interna, na segunda parte do curso o foco esteve em olhar para o que existe fora da enseada de Botafogo. Na primeira aula do bloco "Educação no Mundo", discutimos o artigo científico The MIT School of Law, em que o autor especula como seria a grade curricular de um hipotético curso de Direito no Massachusetts Institute of Technology (MIT). Para Daniel Katz, a organização do mercado jurídico mundial está mudando de forma severa nos últimos anos em virtude dos avanços tecnológicos, da desregulamentação do setor e da pressão dos players do mercado jurídico por um aumento de eficiência. Para o autor, dentro do contexto desses três vetores de mudança, é justamente em um centro de tecnologia como o MIT que está o futuro da educação jurídica. ${ }^{12}$

No encontro seguinte, nos debruçamos sobre experiências vanguardistas em educação no mundo. Fizemos um estudo de caso e analisamos as iniciativas do Cousera, do EdX e da Universidade Minerva ${ }^{13}$. Por fim, como fechamento do segundo bloco, discutimos as contribuições da pedagogia neurocientífica. A partir de estudos recentes envolvendo neurociência e educação, refletimos sobre aspectos estruturais da FGV DIREITO RIO. Em geral, muitas discussões envolvendo educação deixam de inserir pontos que são sedimentados nos estudos de psicólogos e de neurocientistas sobre o comportamento e a cognição humana.

Um exemplo de reflexão nesse sentido que ocorreu durante o curso foi sobre o tempo de duração das aulas. Na Fundação Getúlio Vargas, as aulas são desenhadas

12 KATZ, Daniel Martin, The MIT School of Law? A Perspective on Legal Education in the 21st Century. University of Illinois Law Review, No. 5, Outubro, 2014. Disponível em:: http://ssrn.com/abstract=2513397.

${ }_{13}$ Para mais informações sobre o Minerva, visitar: https://www.minerva.kgi.edu/ 
para durar 100 minutos, o que é uma extensão temporal incompatível com o que diversos estudos sugerem ser o limiar de atenção de adultos. ${ }^{14}$

\section{INCENTIVOS E AVALIAÇÃO}

Usualmente, os professores recorrem às provas escritas como uma forma de avaliar o desempenho dos alunos. Seguindo vanguardistas propostas do denominado projectbased learning, ${ }^{15}$ em nosso curso, os alunos foram avaliados com base em um projeto que tiveram que ir desenvolvendo ao longo de todo o semestre.

Individualmente ou em duplas, todos tiveram que elaborar um relatório de até cinco páginas e uma apresentação de cinco minutos, análoga aos famosos pitches que startups costumam fazer para potenciais investidores. Tanto na apresentação como no relatório os alunos tiveram que (i) identificar com clareza pelo menos um fenômeno institucional da FGV DIREITO RIO que pudesse ser considerado um problema, justificando essa caracterização; (ii) decompor o problema em problemas menores, explicitando suas causas e implicações; e (iii) sugerir uma alternativa para correção do problema identificado.

Os critérios de correção foram fixados de forma alinhada com os objetivos do treino. Assim, os alunos receberam notas de acordo com a desenvoltura nas habilidades críticas, analíticas e criativas ao formular e ao tentar resolver um problema. O relatório e a apresentação tiveram o mesmo peso, representando cada um 50\% da nota total. Além disso, foram definidos dois prêmios, uma premiação para o melhor relatório, denominada "Prêmio Silvio Meira", e outra para a melhor apresentação, chamada de "Prêmio Steve Jobs". Esses prêmios foram pensados como um incentivo à excelência na elaboração dos trabalhos.

Em relação à apresentação final, cabe destacar as especificidades do seu formato. No último dos sete encontros do curso, todos os alunos inscritos fizeram as suas apresentações para uma banca formada por nós, professores da disciplina, e pelos professores convidados: Diego Werneck, Eduardo Jordão e Thiago Bottino. Ao invés da sala de aula, as apresentações foram feitas no hall de entrada da graduação de forma que uma plateia também pudesse assistir aos pitches. No dia do evento, tivemos 14 alunos apresentando trabalhos e cerca de 200 pessoas presentes, entre professores e alunos da Escola que não se inscreveram na disciplina. Considerando que a FGV DIREITO RIO possui um corpo discente total de cerca de 250 pessoas, o evento contou com ampla adesão dos alunos da Escola.

Após cada apresentação de cinco minutos, a banca pôde fazer uma arguição de dez minutos. Ao final de todas as apresentações, cada membro da banca pôde votar no melhor trabalho. Além disso, as pessoas na plateia também puderam participar e o

14 Sobre o adult span attention, visitar: https://en.wikipedia.org/wiki/Attention_span

15 Project-based learning é um método de ensino no qual o aluno aprende por meio da estruturação de um projeto, por um período de tempo razoável, que busca engajar o aluno na resolução de determinado desafio ou problema complexo. 
trabalho mais votado pela plateia recebeu uma indicação para o prêmio com o mesmo peso dos votos dos membros da banca.

\section{Resultados}

No final de 2015, encerramos o curso extremamente contentes com a qualidade dos trabalhos apresentados pelos alunos. Neste sentido, gostaríamos de anexar a este ensaio os dois trabalhos que foram premiados. Luiz Penner e Waldo Ramalho escreveram um elegante texto problematizando a forma como os alunos normalmente são avaliados. Como solução, criaram o mecanismo do paper option, um track alternativo em que os alunos poderiam substituir as provas pela elaboração de um paper. No novo modelo de avaliação proposto seriam inseridos elementos de pesquisa científica no trabalho a ser avaliado.

Harllos Arthur e Pedro Costa, vencedores do prêmio de melhor apresentação, retomaram às bases do projeto pedagógico da Escola e identificaram que, apesar de estar muito claro no projeto fundador o desejo de formar quadros dirigentes para a administração pública, essa vertente de carreira era muito pouco explorada dentro de nossa Escola. Desse forma, eles sugeriram a criação de um Laboratório de Políticas Públicas (Lab), uma instituição gerida por alunos e que se comportaria de forma semelhante a uma empresa júnior. No lugar de prestar consultoria para micro e pequenas empresas, o Lab atenderia órgãos e entidades públicas, como secretarias de pequenos Municípios. Este seria um espaço de iniciação profissional para aqueles que pretendem seguir carreira como gestores públicos.

A iniciativa do Laboratório nos deixa ainda mais satisfeitos por ter ido além da elaboração de um bom trabalho acadêmico. Harllos, Pedro e Fernanda Almeida estão executando o projeto desde o início de 2016 sob supervisão do professor Felipe Fontes. Recentemente, finalizaram o projeto com seu primeiro cliente: a Agetransp, uma agência reguladora responsável por regular e fiscalizar os serviços públicos concedidos de transportes no estado do Rio de Janeiro. $\mathrm{O}$ projeto envolveu a elaboração de uma análise sobre captação, gestão e uso de novas receitas acessórias do metrô (MetroRio) e da linha de trem (SuperVia) do Rio de Janeiro. Potencialmente, o trabalho desenvolvido pela consultoria do Lab pode contribuir para reduzir o valor da tarifa destes modais e impactar a vida de cerca de 2 milhões de pessoas. Cabe dizer que esse projeto não é circunstancial, uma vez que o Lab foi institucionalizado e já existem outros clientes interessados na consultoria pro bono.

Por fim, cabe dizer que, mesmo sem receber nenhum prêmio, outros trabalhos saíram do papel e foram executados, representando, na prática, uma tentativa de corrigir um problema detectado. Essa é a grande virtude do project-based learning, orientar o processo educativo em torno de um problema real e que provoque identificação sincera no aluno.

Nessa linha, merece especial ênfase o trabalho de Marcelo Mattos e Ricardo Carrion. Os dois alunos formularam como um problema da FGV DIREITO RIO o fato 
de a Escola ser ainda pouco conhecida fora do Rio de Janeiro e não reunir no seu corpo discente os melhores alunos das mais diversas regiões do país.

Como solução, houve a proposta de realização de um Curso de Inverno, uma ação institucional de marketing de conteúdo ${ }^{16}$ em que alunos de diversas regiões do Brasil seriam convidados a fazer um curso gratuito de curta duração na FGV DIREITO RIO. Neste curso, os alunos teriam a oportunidade de conhecer o método da Escola, as linhas de pesquisa, os professores e as instalações - vivenciando por um curto período de tempo a experiência que nossos alunos costumam ter.

Cerca de seis meses após o encerramento da nossa disciplina, o Curso de Inverno foi executado com excelência e teve ótimos resultados. Sob um formato de 5 dias intensivos de curso com aulas sobre temas como Direito e igualdade de gênero, Law and Economics e E-democracy, mais de 160 alunos de todas as regiões do Brasil se inscreveram, sendo, inclusive, necessário fazer uma seleção de 60 alunos em virtude das restrições de espaço. Houve, também, inscritos de diferentes condições socioeconômicas, uma vez que, além da gratuidade do curso, alguns alunos com real necessidade financeira tiveram um auxílio de translado e de hospedagem. Por último, cabe ainda ressaltar que o curso de inverno recebeu inscrições de alunos egressos de algumas das mais tradicionais faculdades de Direito do Brasil como UERJ, UFMG, UnB, UFPE e USP. ${ }^{17}$

\section{OPEN-SOURCE}

Apesar das inovações que a disciplina trouxe, esse curso ainda é um esforço pequeno diante do meta-problema que ele pretende enfrentar. As críticas de San Tiago Dantas feitas à educação jurídica brasileira nos anos 50 continuam atuais, com pouco tendo mudado no cenário nacional. ${ }^{18}$

Mesmo dentro da FGV DIREITO RIO, uma Escola que nasceu como antítese para a crise, luta-se para construir uma resposta. Por isso, o curso que ministramos é open source. Seu "código" é aberto e o que foi feito até aqui está disponível para ser usado, aprimorado e compartilhado. Todos as aulas do curso foram gravadas e foi elaborado um material didático, que inclui textos escritos pelos professores e as leituras obrigatórias de cada aula. Todo esse material está disponibilizado nos endereços www.joaquimfalcao.com.br e $\underline{w w w . p e d r o d e l f i n o . c o m}$.

Indo além dos resultados diretos e sensíveis, foi perceptível, principalmente no evento de encerramento, o envolvimento de nossa comunidade com esta iniciativa.

\footnotetext{
${ }^{16}$ Marketing de conteúdo é uma abordagem estratégica de marketing focada em criar e distribuir conteúdo relevante, consistente e valoroso com a finalidade de atrair um determinado público-alvo e associar valores positivos a determinada marca.

17 Mais detahes sobre a primeira edição do Curso de Inverno podem ser encontrados no link: http://direitorio.fgv.br/curso/curso-de-inverno

18 DANTAS, F. C. de San Tiago. A Educação Jurídica e a Crise Brasileira. Educação Jurídica e Método de Caso. Série Cadernos FGV Direito Rio, Educação e Direito, v. 3, Rio de Janeiro, Fevereiro de 2009.
} 
Este curso contribuiu para resgatar valores que foram muito latentes na criação de nossa Escola e que estavam enfraquecidos. Esperamos que os bons ventos do experimentalismo e do espírito reformista continuem a soprar na FGV DIREITO RIO e ecoem pelo Brasil. A nossa Escola sempre foi, é e continuará sendo um projeto em construção.

\section{ANEXO I}

Trabalho de Conclusão - ATCE FGV Direito Rio: Um projeto em Construção

Tema: Escola formadora de líderes para o Direito ou de líderes para o Brasil?

Alunos: Pedro Costa, Harllos Arthur e Fernanda Almeida

Professores: Joaquim Falcão e Pedro Delfino

\section{Introdução}

O presente trabalho está estruturado a partir de alguns problemas que identificamos na atual conjuntura da FGV Direito Rio, a partir de um raciocínio crítico objetivo sobre a situação de momento da Escola. A identificação de tais problemas e a proposta de intervenção que fazemos para solucioná-los foram construídos por meio de uma análise da formação geral oferecida atualmente na Escola em comparação com as premissas que pautaram sua criação e com os objetivos estabelecidos em seu projeto fundador.

Para tanto, reconhecemos, com clareza, a existência do diálogo que os textos de Mangabeira Unger, Caio Farah e Joaquim Falcão estabelecem com a crise das carreiras jurídicas no cenário brasileiro contemporâneo e a importância da proposta de concepção de uma nova faculdade de Direito para o país com uma intenção básica: a formação de lideranças diversas capazes de orientar os rumos do Brasil.

Nesse sentido, cabe apontar os perfis principais de operadores de institutos jurídicos que o projeto fundador ilustra, quais sejam: advogados globais, homens e mulheres de negócios (businessmen e businesswomen) e dirigentes da Administração Pública. A partir daí, é necessária a compreensão de que todas as estruturas sobre as quais as atividades da Escola se baseiam deveriam ser direcionadas para a geração desses três perfis profissionais. 
No entanto, diversos descompassos entre o projeto fundador e a realidade atual da Escola são visíveis. De fato, para atingir os ambiciosos objetivos apresentados no projeto fundador, é necessária uma multiplicidade de instrumentos, ainda pouco desenvolvidos, para concretizar a formação dos perfis profissionais desejados.

Dentro do grande universo de possibilidades para as críticas e a propositura de soluções, escolhemos abordar o seguinte problema: não há um espaço organizado para o desenvolvimento de habilidades específicas de alunos interessados em compor os quadros dirigentes da Administração Pública. Assumindo a importância desse perfil dentro do projeto fundador e a necessidade premente desse tipo de qualificação para o país, iremos expor a seguir as razões pelas quais identificamos esse problema na Escola e, por fim, iremos propor uma intervenção inovadora que pretende contribuir para sua solução.

Nossa observação básica é de que não existe hoje na FGV Direito Rio um espaço capaz de canalizar os interesses dos alunos interessados em trabalhar na Admnistração Pública. Para essa afirmativa, nos baseamos unicamente na análise de atividades extracurriculares, a fim de evitar questionamentos profundos sobre as disciplinas obrigatórias e eletivas oferecidas e sua utilidade para promover a formação desse perfil profissional específico.

Atualmente, alunos com interesse em atuar no setor público encontram poucas ferramentas de entrada em tal mercado, e tampouco instrumentos para desenvolver as habilidades necessárias para uma futura atuação profissional como gestor do Estado. Os espaços existentes estão muito restritos às carreiras jurídicas tradicionais, ainda que com certo vínculo a atividades estatais, como por exemplo a Clínica de Direitos Fundamentais e a Atividade Monitorada de Férias. São ofertadas atividades em órgãos públicos como a Defensoria Pública, o Ministério Público e o Poder Judiciário ou ainda a produção de memoriais de amicus curiae em casos de impacto social relevantes a serem decididos no Supremo Tribunal Federal.

Além disso, não há incentivos institucionais concretos para que os alunos que intencionam seguir essa carreira se engajarem em projetos relacionados com a área. Os alunos não são direcionados a desenvolver um contato precoce com as necessidades e desafios do setor público brasileiro e, limitados à abordagem predominantemente 
jurídica das cadeiras de prática (estágio, clínicas, atividade monitorada e pesquisa), concluem o curso sem as habilidades essenciais à entrada na carreira de gestão pública.

Tendo em vista esse cenário, compreendemos que o projeto fundador da Escola e o desejo de formar lideranças para o futuro do Brasil, em especial o perfil de dirigentes da Administração Pública necessita de um espaço próprio, em que a criatividade social, a capacidade prática de lidar com problemas complexos e os conhecimentos básicos de elaboração de políticas públicas sejam treinados.

\section{Estrutura do Projeto de Solução:}

A solução consiste na criação do Laboratório de Políticas Públicas, gerenciado por alunos da FGV Direito Rio em parceria com professores e pesquisadores da Escola. $\mathrm{O}$ Laboratório funciona como uma plataforma de elaboração de projetos de políticas públicas de âmbito local, que contam com o engajamento e a participação de alunos para seu desenvolvimento.

Para melhor entendimento da proposta, cabe esclarecer os dois níveis em que a atuação de alunos da Escola ocorre:

1) Alunos organizadores do Laboratório: são os responsáveis pelo delineamento dos desafios que serão lançados. Realizam o contato com as entidades públicas interessadas em trazer problemas a serem solucionados pelo Laboratório. Organizam as atividades dos alunos participantes, as palestras a eles oferecidas, o programa de orientação para desenvolvimento dos projetos e conduzem o processo seletivo dos participantes do Laboratório.

2) Alunos participantes do Laboratório: são os agentes ativos da concepção e desenvolvimento das políticas públicas propostos como desafio pelo Laboratório. Produzirão um produto final a ser entregue ao fim do ciclo do Laboratório e buscarão parcerias internas e externas para viabilizar os projetos criados por eles próprios. 
De maneira geral, a proposta pode ser assim representada:

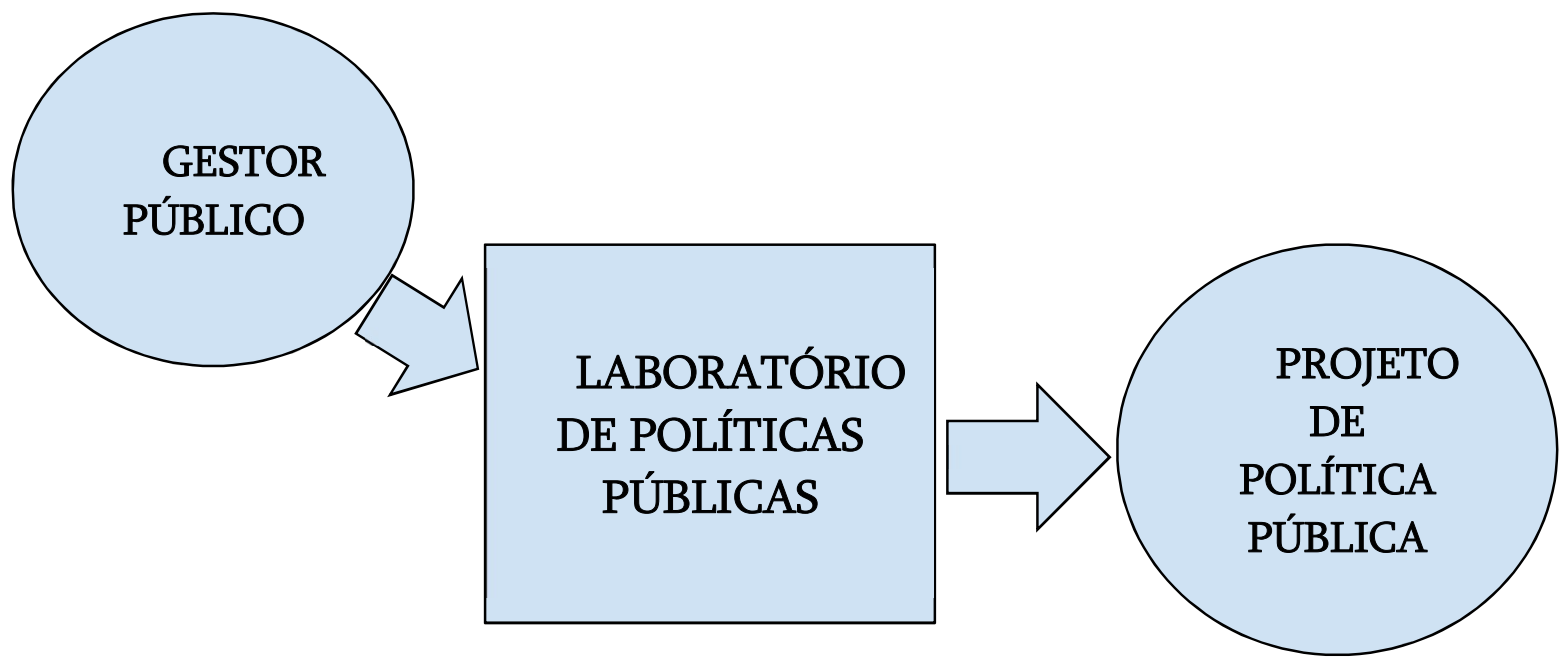

\section{Experiência de implementação do Laboratório:}

No primeiro semestre de 2016, o projeto do Laboratório de Políticas Públicas foi desenvolvido como uma Atividade Complementar Eletiva (ATCE), integrada na grade curricular da Escola de Direito. Sua estrutura gerencial foi composta por um grupo de três alunos da FGV Direito Rio, com a participação de um professor orientador e de uma pesquisadora da área de políticas públicas para a organização do espaço.

Em primeiro lugar, coube ao grupo organizador a definição das atividades a serem realizadas ao longo do semestre. Algumas dessas atribuições a serem mencionadas: (i) a realização de um processo seletivo para compor a equipe de trabalho do Laboratório, (ii) a definição de conteúdos básicos sobre a temática de políticas públicas a ser discutida entre os participantes, (iii) a concepção de dinâmicas interativas para abordagem de casos concretos relacionados ao ciclo de políticas públicas e (iv) prospecção de parceiro público para a realização do trabalho de consultoria gratuita em políticas públicas.

Em especial, a busca por um ente público interessado em repassar demandas de políticas públicas para a apreciação do Laboratório constituiu um grande desafio. Foi 
realizada uma sondagem de problemas das mais distintas fontes, em um intenso trabalho de contato com instituições públicas. Nestas tratativas, houve o esclarecimento dos serviços oferecidos pelo Laboratório em favor do órgão público em questão e, em especial, de seu caráter não-profissional, experimental e educativo.

Durante a prospecção da consultoria a ser realizada, a orientação do professor e da pesquisadora vinculados ao Laboratório teve papel fundamental de auxílio aos alunos organizadores, por meio do acionamento suas redes de contato externas à FGV Direito Rio para a captação de problemas sociais diversos e instigantes. Além disso, sua participação foi decisiva para a delimitação do escopo do trabalho a ser realizado pelo grupo, ao analisar as demandas apresentadas pelo parceiro público de maneira a adequá-las às limitações e possibilidades do Laboratório.

Neste semestre, a parceria foi firmada com a Agência Reguladora de Serviços Públicos Concedidos de Transportes Aquaviários, Ferroviários, Metroviários e de Rodovias (AGETRANSP), entidade da administração pública indireta do Estado do Rio de Janeiro. Portanto, a partir da definição do parceiro público inicial, avançou-se para a definição de um recorte temático de problema real enfrentado pelo gestor público apresentado ao Laboratório, sobre o qual todos os participantes se debruçariam ao longo do ciclo de funcionamento da plataforma. O objeto do estudo produzido foi a regulação das receitas extraordinárias nos sistemas de metrô e trens do Rio de Janeiro, operado por concessionárias privadas.

O funcionamento do Laboratório de Políticas Públicas ocorreu por meio de encontros semanais, em que eram realizadas discussões sobre diversos assuntos relacionados à temática das políticas públicas, apresentações de casos pelos participantes, realização de dinâmicas de grupo em simulação de situações reais de tomada de decisão estratégica, bem como diálogos com gestores e pessoas envolvidas com a realidade governamental, no intuito de compartilhar experiências. Os encontros também constituíam essencialmente o espaço de trocas e discussões acerca da consultoria prestada ao parceiro público, por meio da crítica construtiva aos resultados de pesquisa e definição de etapas e responsabilidades para a execução do relatório escrito a ser entregue ao órgão de governo.

Durante a primeira fase de implementação do laboratório, encontraram-se algumas dificuldades. Essas dificuldades giraram em torno da inexperiência do grupo 
organizador em relação às atividades exigidas pelo Laboratório, tais como: o relacionamento com um órgão público; a organização de um projeto relativamente complexo com a participação de dez alunos de graduação; e a conciliação do Laboratório com demais atividades da graduação. Ainda assim, ao término do primeiro ciclo e avaliação interna do semestre, acreditamos que o Laboratório alcançou êxito e provou ser uma ideia promissora tanto para os alunos quanto para a Escola.

Diante disso, pretendemos avançar ainda mais no desenvolvimento do projeto do Laboratório de Políticas Públicas, com o intuito de torná-lo um legado sólido e perene para a FGV Direito Rio. A partir do segundo semestre de 2016, a equipe coordenadora do Laboratório, a partir da experiência adquirida no primeiro ciclo de atividades, busca conceber uma nova estrutura para o Laboratório, de modo que sua existência se desvincule da figura pessoal de seus criadores, conquistando independência de quem o organiza. Para tanto, pretende-se convocar mais estudantes que tenham interesse em fazer parte da equipe; firmar parcerias com mais órgãos públicos e elaborar uma organização interna inspirada nos moldes de uma empresa júnior.

Esta é a forma que acreditamos ser ideal para assegurar a sua continuidade no âmbito da comunidade universitária, trazendo benefícios concretos e permanentes a serem percebidos pela Escola de Direito por meio da institucionalização desta iniciativa. Os trabalhos desenvolvidos no Laboratório permitirão o desenvolvimento das seguintes habilidades, fundamentais na preparação de futuros dirigentes da Administração Pública: i) elaborar projetos de políticas públicas; ii) lidar na prática com os desafios enfrentados pela gestão pública; iii) trabalhar em equipe para a criação de projetos de impacto social; iv) analisar problemas sociais complexos e propor soluções inovadoras. Por fim, o Laboratório terá maiores condições de se afirmar como um importante espaço para a formação de uma rede de contatos entre os alunos e os profissionais da área, gerando uma comunidade até então inexistente na FGV Direito Rio de jovens engajados na carreira de gestão pública.

\section{ANEXO II}




\section{Alternativas ao aprendizado conteudista no ensino jurídico ${ }^{19}$ Por Luiz Carlos Penner e Waldo Ramalho}

\section{O problema}

A FGV Direito Rio é um dos poucos empreendimentos de educação jurídica do mundo que tenta desafiar os projetos pedagógicos e institucionais tradicionais (Ribeiro e Vargas, 2014), reunindo, também, recursos humanos, infraestrutura e gestão sem precedentes para uma faculdade de direito brasileira. Para conseguir realizar este objetivo, é necessário que seus alunos tenham uma formação que os leve a perfis distintos daquele do jurista clássico. ${ }^{20}$ No entanto, por mais que a FGV Direito Rio busque este objetivo, ainda há alguns para sua efetivação.

O objetivo deste ensaio é permitir uma reflexão sobre a proposta de enfoque na habilidade de pesquisa como método libertador do aluno de uma formação voltada para o manualismo e passividade - entendida como falta de mecanismos de autodidatismo. ${ }^{21}$

Entendemos que os principais obstáculos enfrentados são: (i) o enciclopedismo ${ }^{22}$, (ii) a inércia dos alunos em relação às suas escolhas quanto ao seu próprio aprendizado e (iii) resistências tanto pelo mercado de trabalho quanto por parte do corpo docente e discente frente ao projeto pedagógico inovador da Escola.

Sobre o primeiro obstáculo, o profissional de alto nível não é aquele que detém a maior quantidade de informações acerca de determinado tema, mas sim aquele capaz de manejar conhecimentos para construir soluções para o problema - soluções estas que serão tanto melhores quanto mais inovadoras, alternativas e eficientes.

\footnotetext{
${ }_{19}$ Agradecemos aos professores Diego Werneck Arguelhes e Fernando Leal pelo diálogo aberto, pelas críticas construtivas e ideias que nos levaram a este artigo. Também agradecemos aos professores Patrícia Pinheiro Sampaio e Antonio Carlos Porto Gonçalves cujas críticas, mantida as discordâncias, ajudaram a melhorar este trabalho. Por fim, agradecemos ao professor Eduardo Magrani pelas recomendações finais na conclusão deste artigo.

20 Sobre isto, ver caracterização de (Vargas, 2014) sobre o jurista clássico: “O jurista clássico é um oficialista. O ponto de partida para compreender sua prática social é o direito positivo. O jurista clássico se vê como agente do interesse público e, no desempenho de suas funções, busca atuar nos limites estritos da sua competência, estabelecida, em última análise, pela constituição e pelas leis aprovadas pelo Congresso. Ao aplicar a lei para dirimir conflito em caso concreto, o jurista clássico não cria, apenas traduz vontade popular, previamente disciplinada em nível abstrato. E ao desempenhar seu papel de forma consistente, o jurista clássico entende contribuir para realizar a vontade do povo e os ideais de justiça nos quatro cantos do país".

${ }^{21}$ É importante ressaltar que não consideramos que o método voltado para habilidades e pro atividade dos alunos é necessariamente o melhor método possível. O que pretendemos com este ensaio é estabelecer que, dados os objetivos da FGV Direito Rio serem neste sentido, devemos buscar métodos para concretizá-los no dia a dia da faculdade.

${ }^{22}$ A definição de enciclopedismo é dada por Unger (2005) ao dizer que: “O ensino jurídico [...] continua distante tanto de um pensamento verdadeiramente teórico quanto de uma utilidade profissional imediata. Sem servir nem à teoria nem à prática, resvala na tentativa de casar um amontoado de regras - o conteúdo do direito positivo - com um sistema fossilizado de conceitos doutrinários".
} 
Neste contexto, o foco da formação acadêmica deveria ser modificado, da reprodução pura dos saberes para a apreensão de conteúdo voltada para a formação de habilidades. Dentre as habilidades essenciais podemos destacar as habilidades (i) analíticas, (ii) críticas, (iii) criativas, (iv) emocionais e (v) interpessoais.

Dentro destas habilidades principais, podemos subdividi-las em habilidades mais específicas, de fácil compreensão e aplicação prática. Uma destas é a habilidade de pesquisa - foco deste ensaio - que permite o desenvolvimento de habilidades analíticas, críticas e criativas.

Em relação ao segundo problema, a passividade dos alunos sobre sua formação acadêmica, podemos identificar dois cenários distintos, ambos retirando do aluno o protagonismo na construção de sua própria formação. O primeiro é de uma faculdade tradicional com aulas majoritariamente expositivas, nas quais os alunos apenas absorvem a maior quantidade possível de conteúdo ensinado pelo professor. $\mathrm{O}$ segundo cenário é um pouco melhor e mais próximo ao que ocorre na FGV Direito Rio. Refere-se a uma passividade no sentido de que os alunos, por mais que sejam incentivados a se preparar para as aulas - cujo método será socrático ou dialogado possivelmente não desenvolvem habilidades para adquirir autonomia intelectual.

Mesmo nesta segunda hipótese, a atuação dos alunos se resume a ler os textos indicados pelos professores, a partir de determinadas instruções, para que haja uma boa discussão em sala de aula. É claro que esta orientação é muito importante, mas é necessário que existam outros mecanismos aliados a esta abordagem para estimular o desenvolvimento de habilidades - dentre elas, a habilidade de pesquisa - e de uma postura que permita o autodidatismo em determinado momento de suas formações. Com o autodidatismo pretende-se que o aluno seja capaz de aprender a fazer sozinho as perguntas corretas para guiar a resolução de um problema, de modo que consiga buscar o melhor material jurídico e as melhores respostas para solucioná-lo.

Acreditamos que a ampliação das possibilidades de desenvolver habilidades de pesquisa é um mecanismo de baixo custo que pode modificar o enfoque atual da FGV Direito Rio em direção ao objetivo da faculdade. Passaremos a privilegiar habilidades em detrimento de conteudismo puro e também a privilegiar uma postura ativa dos alunos.

Quanto ao terceiro problema, de ordem externa à própria faculdade, podemos dizer que há uma grande descrença no enfoque dado pela FGV Direito Rio às habilidades em detrimento do aprendizado conteudista. Há uma crença disseminada pela comunidade jurídica que o melhor profissional do direito é aquele que tem conhecimentos quase exaustivos sobre a doutrina, lei e jurisprudência. O projeto da FGV Direito Rio aposta justamente no reconhecimento da importância de estudar o direito, mas isto não significa restringir o papel da faculdade. ${ }^{23} \mathrm{~A}$ habilidade de pesquisa será capaz de mostrar a estas pessoas, docentes e discentes, que o ato de

23 Sobre esta resistência a inovações, ver UNGER 2005, p. 16: "Mais do que qualquer obstáculo prático, pesará contra a proposta sua novidade. É uma antipatia que pode ser agravada pela falta de costume, no Brasil, de abraçar projetos que não hajam sido referendados antes por alguns dos centros de cultura que nos acostumamos a imitar". 
pesquisar está no cerne de qualquer profissão jurídica, principalmente aquelas que lidam com áreas de vanguarda.

Imaginamos que um advogado, procurador, magistrado, acadêmico, regulador, empreendedor ou educador não será capaz de lidar com a velocidade da mudança dos materiais autoritativos do direito - leia-se principalmente leis e jurisprudência- sem que seja treinado com base em habilidades para se adequar e estar à frente das mudanças. Para educar pessoas para profissões que ainda não existem, para contextos que ainda irão surgir, é necessário que tenham autonomia intelectual e habilidades metatécnicas. Conteúdos tornam-se obsoletos, diferentemente de habilidades: uma pessoa com habilidades interpessoais não as perde com uma mudança de legislação.

Tendo em vista estes três obstáculos, acreditamos que é preciso que o ensino seja cada vez mais integrado à pesquisa - não apenas no sentido acadêmico. As oficinas de pesquisa, embora sejam iniciativas dignas de elogios, são um momento compartimentalizado e não modificam o dia a dia do aluno da FGV. Nas oficinas de pesquisa, o aluno sofre uma série de limitações para o desenvolvimento de sua habilidade de pesquisa de forma adequada. Podemos destacar duas: (i) o trabalho é sempre realizado em grupo, o que gera uma situação de segurança e permite com que nem todos os alunos desenvolvam habilidades de pesquisa de maneira satisfatória e (ii) os temas das pesquisas se limitam àqueles oferecidos pela coordenação, de modo alguns alunos podem não se sentir atraídos por estas áreas, não se dedicando da maneira adequada ao trabalho. Para pesquisar, é preciso ser um aluno ativo e interessado, buscando interagir com o que foi estudado, com foco em produção de novas ideias e análises.

Propomos que o aluno tenha um caminho alternativo ao aprendizado de conteúdo, um caminho que crie uma cultura de pesquisa.

\section{Desenho de uma solução}

Nossa solução é criar um Programa de Artigo de Pesquisa. Alunos interessados poderão escolher uma matéria inscrita neste programa, dentre aquelas que estão matriculados, e, ao invés de realizar as avaliações regulares, irão pesquisar e escrever um paper.

O trabalho resultante desta pesquisa deverá: (a) possuir reflexão original e não mera síntese, ainda que sistemática, de trabalhos acadêmicos; ou (b) ser uma pesquisa empírica, quantitativa ou qualitativa. Com isso, espera-se que o desenvolvimento da habilidade de pesquisa seja reconduzido ao desenvolvimento da habilidade analítica, crítica e criativa.

O objetivo da pesquisa é que o aluno tenha a oportunidade de se aprofundar em temas variados e consiga desenvolver habilidades analíticas (analisar e decompor um problema), críticas (encontrar possíveis falhas no arranjo atual) e criativa (desenvolver uma possível solução para aquela situação analisada). Neste sentido, o trabalho deverá ser original - isto é, não pode ser a explicação de temas que tenham sido lecionados naquela matéria, como um simples "resumo" das aulas. Alternativamente, o trabalho pode ser uma investigação empírica, buscando operacionalizar conceitos apreendidos, 
de modo a observar fenômenos do mundo real, sistemática e metodologicamente, justificando a realização do trabalho ${ }^{24} 25$.

O mecanismo de avaliação será realizado em três etapas consecutivas: (i) blind review por alunos voluntários; (ii) avaliação pelo assistente acadêmico; e (iii) avaliação pelo professor orientador. As notas serão atribuídas unicamente nas etapas (ii) e (iii), de modo que a primeira é responsável apenas por indicar as críticas pertinentes ao artigo. ${ }^{26}$

Este processo opcional de blind peer review estudantil é extremamente importante. Qualquer estudante matriculado nas matérias inscritas no programa daquele semestre poderá se voluntariar para ser um blind reviewer. Ele receberá um trabalho não identificado e deverá apontar falhas da pesquisa. Se a banca avaliadora considerar o parecer do blind reviewer útil, poderá conceder até meio ponto em sua nota naquela matéria.

Um modelo alternativo para que os alunos se sintam incentivados a participar do programa é substituir o modelo de avaliação por uma apresentação dos melhores trabalhos nos seminários de pesquisa da FGV Direito Rio, de modo que os alunos poderão obter feedback da comunidade jurídica ${ }^{27}$. Com isto, os melhores trabalhos poderiam ser publicados na Coleção Jovem Jurista. Juntamente a estes incentivos de publicação e contato com a comunidade acadêmica, poderão ser concedidas horas complementares aos melhores alunos.

Por fim, com qualquer um dos pacotes de incentivo - substituição da prova de uma disciplina pelo paper ou a possibilidade de publicação com horas complementares - os alunos poderão desenvolver algumas das habilidades essenciais ligadas à habilidade de pesquisa e, com isso demonstrar para a comunidade jurídica que devemos incentivar os alunos a serem autodidatas e formados com base no desenvolvimento de habilidades. ${ }^{28}$

${ }^{24}$ Como sabemos que durante o primeiro e segundo períodos da faculdade, os alunos ainda não têm determinados conhecimentos basilares para a realização de uma pesquisa acadêmica, nestes períodos não haverá a possibilidade de participação no Programa de Artigo de Pesquisa.

${ }_{25}$ Como exemplos de pesquisas que podem ser desenvolvidas pelos participantes do programa, podese investigar a tributação de serviços on-demand (como Netflix e Spotify), em Direito Tributário, ou o conhecimento da população carioca - aferido a partir de questionários - sobre seus direitos enquanto consumidores, em Direito do Consumidor.

26 Sugerem-se os seguintes critérios de avaliação: (i) concisão e clareza do texto; (ii) qualidade da pesquisa bibliográfica; (iii) qualidade e relevância da pesquisa empírica ou da reflexão original trazida pelo texto; (iv) se tratar-se de pesquisa empírica, a qualidade dos dados obtidos; (v) o rigor metodológico empregado na pesquisa.

${ }^{28}$ Esta proposta não pretende substituir as oficinas de pesquisa tampouco os programas de iniciação científica. Há particularidades apresentadas anteriormente que a diferencia das oficinas e há duas distinções em relação ao programa de iniciação científica: (i) este é muito voltado para a área de estudo dos professores tempo integral da faculdade, o que gera falta de interesse pelos alunos e também é algo visto como voltado para pessoas que querem seguir carreiras acadêmicas; (ii) há uma grande desvirtuação desses programas, de modo que o aluno muitas vezes não é incentivado a pensar na 
Em suma, o problema identificado neste trabalho é que a FGV DIREITO RIO não está adequadamente voltada para o desenvolvimento de habilidades, mas ainda para a apreensão de conteúdo. Uma das habilidades essenciais em nossa visão é de aprender a pesquisar, como parte integrante do processo de aprendizado. Com isso, propomos uma solução que incentive os alunos na realização de pesquisas de forma integrada à própria grade curricular.

\section{Referências:}

MANGABEIRA, Unger. Uma nova faculdade de Direito no Brasil. Rio de Janeiro: Escola de Direito do Rio de Janeiro da Fundação Getulio Vargas, 2005.

RIBEIRO, Gustavo; VARGAS, Daniel. O Global Legal Education Forum: Mapeando uma nova crise no ensino jurídico e construindo uma agenda propositiva. In: Cadernos FGV DIREITO RIO, v. 9. Rio de Janeiro: FGV DIREITO RIO, 2014.

VARGAS, Daniel. Jurista Criativo. In: Cadernos FGV DIREITO RIO, v. 9. Rio de Janeiro: FGV DIREITO RIO, 2014.

estrutura de sua pesquisa, mas sim realizar tarefas indicadas por algum professor, o que nos reconduz à passividade identificada como obstáculo à proposta da FGV Direito Rio. 